\title{
Modafinil ameliorated pancreatic injury and inflammation through upregulating SNIP1
}

\author{
Jianwu Wu*, Yijie Lu*, Ancheng Qin, Song Li, Bo Huang, Xinwei Jiang and Zhiming Qiao \\ Department of Hepatobiliary and Pancreatic Surgery, Affiliated Suzhou Hospital of Nanjing Medical University, Suzhou \\ Municipal Hospital, Suzhou, Jiangsu, China
}

\begin{abstract}
Acute pancreatitis (AP) is the inflammatory response of the exocrine pancreas to various causes. Modafinil has significant anti-inflammation and anti-oxidation effects. No experiment has assessed the effects of modafinil on AP. Thus, the study aims to study the effects of modafinil on AP and its potential mechanism in vivo and vitro. $5 \%$ sodium taurocholate was retrograde injected into pancreatic duct to establish AP rat model. The severity of AP was detected by H\&E staining, serum amylase and lipase levels. The inflammation, oxidative stress and apoptosis were detected separately by ELISA, MDA and SOD kits, tunnel staining and Western blotting in rats. Besides, SNIP1 expression was analyzed by qPCR and Western blotting. In vivo, AR42J cells were stimulated by cerulein and lipopolysaccharide to establish AP cell model. Flow cytometry examined cell apoptosis. After the plasmids silencing SNIP1 were transfected into AP cells, the inhibitory effects of modafinil on inflammation, oxidative stress and apoptosis were significantly reversed. The results indicated that modafinil showed significant curative and therapeutic effects by regulating SNIP1 levels.
\end{abstract}

Key words: Acute pancreatitis - Modafinil — SNIP1 — Inflammation

\section{Introduction}

Acute pancreatitis (AP) is an inflammatory response in which pancreatic enzymes (such as trypsin, pancrelipase) are activated in the pancreas owing to various causes, leading to pancreatic tissue autodigestion, edema, hemorrhage and necrosis. The acute inflammation and autodigestion of pancreas usually contribute to the release of amylase and lipase into blood. Serum amylase and lipase are used as the diagnose standards in AP (Steinberg et al. 2017). Furthermore, C-reactive protein (CRP) can be applied as an important indicator for detecting pancreatic necrosis in AP patients (Komolafe et al. 2017).

\footnotetext{
* These authors participated equally to this work.

Correspondence to: Xinwei Jiang, Affiliated Suzhou Hospital of Nanjing Medical University, Suzhou Municipal Hospital, 26 Daoqian Street, Gusu District, Suzhou, Jiangsu, 215002, China E-mail: XinweiJiangJiang@163.com Zhiming Qiao, Affiliated Suzhou Hospital of Nanjing Medical University, Suzhou Municipal Hospital, 26 Daoqian Street, Gusu District, Suzhou, Jiangsu, 215002, China E-mail: zhiming_qiao@163.com
}

Modafinil is a wakefulness enhancer used in the treatment of narcolepsy, which includes shift work sleep disorders and obstructive sleep apnea (Lillicrap et al. 2016). In addition to these indications, modafinil is also widely used in other diseases. Animal studies have shown that modafinil can inhibit inflammation via decreasing pro-inflammatory factors and increasing anti-inflammatory factors (Han et al. 2018; Yousefi-Manesh et al. 2019b). In addition, it affects oxidative stress partly by decreasing malondialdehyde (MDA), one of products of membrane lipid peroxidation (Yousefi-Manesh et al. 2019b). And modafinil regulates Akt/NF- $\mathrm{BB}$ pathway to ameliorate inflammation in atherosclerosis mouse with apoE deficiency (Han et al. 2018). Besides, modafinil derivatives exert anti-inflammatory effects much better than aspirin via decreasing iNOS and COX-2 in LPS-treated BV2 microglia cells. Modafinil can also inhibit the apoptosis and autophagy in rapamycin-induced hippocampal neuronal cells (Jung et al. 2012). Furthermore, the systematic review indicates the procognitive effects of modafinil on major depressive disorder (Cao et al. 2019).

Smad nuclear interacting protein1 (SNIP1) is mainly located in the nucleus. SNIP1 interacted with TGF- $\beta$ signal transduction factor Smad4, thus inhibiting the recruitment 
of Smad4 to co-activator $\mathrm{CBP} / \mathrm{p} 300$ and the activation of TGF- $\beta$ downstream genes (Vaccarino et al. 2019). SNIP is proved to be modified at its lysine site by small ubiquitinlike modifier (SUMO) in vitro and in vivo. The SUMOylation of SNIP1 decreased its inhibitory effects on TGF- $\beta$ downstream genes (Liu et al. 2016). TGF- $\beta$ is involved in limiting the development of inflammation process (Schmitz-Winnenthal et al. 2010). Besides, TGF- $\beta$ signal pathway is involved in many cellular processes including cell apoptosis, cell growth, dynamic equilibrium and other functions (Chen et al. 2019; Schlegel et al. 2019; Yang et al. 2019).

It is observed that SNIP1 levels are down-regulated in patients with pancreatitis through searching Gene Expression Omnibus (GEO) database (Chu et al. 2019), implying that SNIP1 may play a vital role in AP. There have been several studies show that SNIP1 modulates epithelial barrier function in intestinal epithelial cells to suppress inflammation and its overexpression decreases cardiac hypertrophy induced by pressure overload via inhibiting nuclear factorкB signaling (Lu et al. 2016; Shi et al. 2018). Furthermore, SNIP1 mediates DNA damage-induced apoptosis through TET2-SNIP1-c-MYC pathway and its knockdown in pituitary adenoma cells suppresses proliferation and induces apoptosis (Chen et al. 2018). Thus, the study mainly focused on the effects of modafinil on AP rats and the potential mechanism in AP.

\section{Methods}

\section{Animals}

The adult Sprague Dawley (SD) rats (weight $230 \pm 30$ g, age $7 \pm 1$ weeks) were purchased by Kay Biological Technology (Shanghai, China) $(n=40)$. All rats were raised at $23-25^{\circ} \mathrm{C}$, and at $50-60 \%$ humidity. The rats were divided into AP group $(n=30)$ and Control (Sham) group $(n=10)$. The rats in the AP group were used to establish AP model. The rats were anesthetized by intraperitoneal injection with $3 \%$ pentobarbital sodium (Chemmrrt, Beijing, China). After incision in the middle of the abdomen of rats, duodenum was exposed, and pancreatic and hilar bile ducts were differentiated. Biliopancreatic duct was temporarily blocked using an arteryclamp. The catheter was used to enter biliopancreatic duct transduodenally. 5\% sodium taurocholate (Sangon Biotech, Shanghai, China) was retrograde injected into pancreatic duct $(1 \mathrm{mg} / \mathrm{kg})$. For Control group, the rats were injected into the same amount of normal saline under same laparotomy treatment. After surgery, the rats were intraperitoneally administered with modafinil (10 $\mathrm{mg} / \mathrm{kg}$, Sigma-Aldrich, Merck KGaA, Germany) dissolved in dimethyl sulfoxide (50\% DMSO) once daily for 3 days
(AP+modafinil group). The dose of modafinil could exert protective roles partly through reducing inflammation (Yousefi-Manesh et al. 2019b). In addition, the preliminary study showed that the dose of modafinil could ameliorate pancreatic injury.

The Control group was administered with equal amount of DMSO. After final modafinil treatment, the rats were anesthetized by pentobarbital sodium and fixed on the operating table. The ascites were extracted with a $5 \mathrm{ml}$ syringe and the result was recorded. Blood was collected from the abdominal aorta, placed in the sterilized EP tube and centrifuged at $3000 \mathrm{rpm}$ at $4^{\circ} \mathrm{C}$ for $10 \mathrm{~min}$. After $40 \mathrm{~min}$, the supernatant was collected and stored at $-70^{\circ} \mathrm{C}$. The intact pancreatic tissue was also taken out, the section of which was fixed with $4 \%$ paraformaldehyde. The rats were sacrificed by pentobarbital sodium. The rest of the pancreas was stored in liquid nitrogen for further experiment.

All experiments were performed according to Ethics Committee of Suzhou Municipal Hospital (KL901099).

\section{The detection of amylase and lipase}

The amylase and lipase content in serum was separately detected by amylase or lipase assay kit according to the manufacturer's protocol (amylase kit: C016-1-1. lipase kit: A054-1-1, Nanjing JianCheng, Nanjing, China).

\section{Western blot}

Pancreas tissue was taken and cut into pieces, which were cleaved by protein lysate. Pancreas tissue lysate was centrifuged at $12000 \mathrm{rpm}$ for $10 \mathrm{~min}$. The supernatant was collected and used to detect total protein concentration. Subsequently, the target proteins were separated by using SDS-PAGE electrophoresis and then transferred into PVDF membrane. Skim milk was used to block the protein bands, followed by routine washing. Afterwards, diluted primary antibody was added and incubated with target protein at $4^{\circ} \mathrm{C}$ overnight (Bcl-2: \#3498, caspase-3: \#9662, cleaved caspase-3: \#9664, Bax: \#14796, GADPH: \#5174, CST, USA. SNIP1, ab126194, England). The bands were washed and incubated at $37^{\circ} \mathrm{C}$ for $2 \mathrm{~h}$. After ECL developed color, Image J software was used to analyze gray value. The relative expression of target protein was calculated by the formula: target protein band gray value/GADPH gray value.

\section{Hematoxylin and eosin (H\&E) staining}

Paraffin sections of pancreatic tissue were prepared for H\&E staining (Liu et al. 2018). Schmidt pathology score method was used to assess damage of pancreatic tissue (Liu et al. 2017) (Table 1). The scoring process was as following: 5 fields were randomly selected from each section, which were indi- 
Table 1. Histopathological scoring criteria of rat pancreas (Schmidt method)

\begin{tabular}{|c|c|c|c|c|c|}
\hline & 0 & 1 & 2 & 3 & 4 \\
\hline Edema & No & $\begin{array}{c}\text { regional edema of lobular } \\
\text { septa } \\
\end{array}$ & $\begin{array}{c}\text { diffused edema of lobular } \\
\text { septa } \\
\end{array}$ & $\begin{array}{l}\text { acini swelling, diffused } \\
\text { expansion of acinar septa }\end{array}$ & $\begin{array}{c}\text { pulmonary lobules } \\
\text { clearly separated }\end{array}$ \\
\hline Inflammation & No & 2-10 (white blood cell)/HPF & $11-20 / \mathrm{HPF}$ & $21-30 / \mathrm{HPF}$ & $>30 / \mathrm{HPF}$ \\
\hline Bleeding & No & $0-25 \%$ & $25-50 \%$ & $50-70 \%$ & $>75 \%$ \\
\hline Necrosis & No & The surrounding of the gland & $<20 \%$ & $20-50 \%$ & $>50 \%$ \\
\hline
\end{tabular}

HPF, high-power field.

vidually graded through the four aspects of edema, inflammation, bleeding and necrosis. Then, the average scores of the 5 fields were taken as the final score. The higher score stood for more severe damage of pancreatic tissue.

\section{ELISA}

TNF- $\alpha$ (tumor necrosis factor $\alpha$ ), IL-6 (interleukin 6) and CRP levels in serum were separately detected using corresponding kits by the manufacturer's protocol (TNF- $\alpha$ : RABo479, IL-6: RAB0311, or CRP kit: RAB0097. SigmaAldrich, Merck KGaA, Germany).

The detection of super oxide dismutase (SOD) and malondialdehyde (MDA)

The pancreatic tissue was homogenized and centrifuged to collect the supernatant. Oxidative stress parameters were evaluated by oxidative stress parameters (SOD and MDA). SOD levels were analyzed by total superoxide dismutase assay kit with nitro blue tetrazolium (NBT; S0109, Beyotime, Shanghai, China). MDA was detected by thiobarbituric acid method according to the manufacturer's protocol (S0131).

\section{Tunnel staining}

Paraffin section of pancreatic tissue was prepared for TUNNEL staining (MK1027, Boster, Wuhan, China). The paraffin section was deparaffinized using xylene I for 15 min and then using xylene II for 15 min. Afterwards, the section was in turn soaked into absolute alcohol for $20 \mathrm{~min}, 95 \%$ ethanol for $5 \mathrm{~min}, 90 \%$ ethanol for $5 \mathrm{~min}$, $85 \%$ ethanol for $3 \mathrm{~min}$ and washed with distilled water for $2 \mathrm{~min}$. DNase-free proteinase $\mathrm{K}(20 \mu \mathrm{g} / \mathrm{ml})$ was added to the sections and incubated with sections for $20 \mathrm{~min}$ at $20^{\circ} \mathrm{C}$. Subsequently, the sections were washed with PBS for three times. The apoptotic cells in pancreatic tissue were stained using TUNNEL kit according to the manufacturer's protocol. The end of DNA 3-OH in apoptotic nucleus of pancreatic tissue was labeled by d UTP notch terminal labeling mediated by terminal deoxynucleotide transferase. Furthermore, the apoptotic cells were labeled and displayed by in situ fluorescence. The apoptotic cells presented green fluorescence and all nucleated cells showed blue fluorescence after DAPI staining.

\section{Cell line}

Acinar cell necrosis was closely correlated with the development of AP. The rat pancreatic acinar AR42J cells were purchased from American type culture collection (YS-ATCC030, Manassas, VA, USA). Cells were cultured at RPMI-1640 medium containing $10 \%$ fetal bovine serum at $37^{\circ} \mathrm{C}$ with $5 \% \mathrm{CO}_{2}$. Cerulein (CR; $0.5 \mathrm{nM}$ ) and lipopolysaccharide (LPS; $1.0 \mu \mathrm{g} / \mathrm{ml}$ ) were used to culture AR42J cells for $12 \mathrm{~h}$ and establish AP cells model. The Control group was treated using equal DMSO. Modafinil was dissolved into DMSO. AR42J cells were pretreated with modafinil for $48 \mathrm{~h}$ at different concentrations $(0.1,1,3$ and $10 \mathrm{mM})$ separately.

\section{Plasmid transfection}

SNIP1 knockdown plasmids (shRNA-SNIP1-1, shRNASNIP1-2) and its negative control (shRNA-SNIP1-NC) were separately transfected into AR42J cells using Lipofectamine 2000 (Invitrogen, England) through the manufacturer's protocol (plasmid: GenePharma, Shanghai, China). Afterwards, the cells were cultured at $37^{\circ} \mathrm{C}$, at $5 \% \mathrm{CO}_{2}$ for $24 \mathrm{~h}$ for further experiment.

\section{CCK8 assay}

Cells were seeded into 96-well plates with $1 \times 10^{4}$ cells in each. $10 \mu \mathrm{l} \mathrm{CCK8}$ solution was added into each well and incubated with cells for $1 \mathrm{~h}$ (Cusabio Biotech, Wuhan, China). The absorbance in $450 \mathrm{~nm}$ was detected using a Microplate Reader.

\section{$R T-q P C R$}

The total RNA was extracted using TRIzol lysate (Invitrogen, CA, USA). Then, we used PrimeScript RT Reagent Kit 
Table 2. The score of pancreatic histopathological changes

\begin{tabular}{lcc}
\hline \multirow{2}{*}{ Group } & \multicolumn{2}{c}{ Time (h) } \\
\cline { 2 - 3 } & $0.52 \pm 0.19$ & 72 \\
\hline Sham & $0.55 \pm 0.17$ & $0.18 \pm 0.14$ \\
Modafinil & $4.41 \pm 1.05^{* *}$ & $11.65 \pm 1.60^{* *}$ \\
AP & $3.42 \pm 0.90^{* *}, \#$ & $7.12 \pm 1.19^{* *}, \#$ \\
AP+modafinil
\end{tabular}

Data are means \pm SD. ${ }^{* *} p<0.01 v s$. Sham group; ${ }^{\#} p<0.05,{ }^{\# \#} p$ $<0.01$ vs. AP group.

(RR047A, Takara, Japan) to reverse transcript total RNA into cDNA. PCR reaction system containing cDNA, SYBR Green mix and primers was performed using the 7500 RealTime PCR Detection System. GAPDH was used as internal parameter. The relative expression of SNIP1 was calculated using $2^{-\Delta \Delta C T}$ method (Chen et al. 2013).

\section{Flow cytometry}

The cells were washed two times with PBS and then incubated with $5 \mu$ l Annexin-V-FITC at room temperature in dark for $15 \mathrm{~min}$. $2.5 \mu \mathrm{l}$ propidine iodide (PI) was added before detection. The flow cytometry was used to cell apoptosis levels. The fourth quadrant (Q4) of the scatter plot stood for health $\left(\mathrm{FITC}^{-} / \mathrm{PI}^{-}\right)$cells. The third quadrant $(\mathrm{Q} 3)$ is viable apoptotic cell $\left(\mathrm{FITC}^{+} / \mathrm{PI}^{-}\right)$and the second quadrant (Q2) is non-viable apoptotic cell $\left(\mathrm{FITC}^{+} / \mathrm{PI}^{+}\right)$. The cell apoptotic rate was calculated by the formula: cell apoptotic rate $=\mathrm{Q} 3$ + Q2 (Liao et al. 2019).

\section{Statistical analysis}

Statistical data was analyzed using GraphPad prism software 7.0. In vivo, the comparison among different groups was performed through two-way analysis of variance followed by Turkey's test. In vitro, comparison beyond two groups was performed with one-way analysis of variance followed by Turkey's test. Data was shown as mean \pm standard deviation (SD). A value $p<0.05$ was considered as statistically significant.

\section{Results}

Modafinil significantly decreased pancreatic damage in AP rats

In Sham group, H\&E staining showed that pancreatic tissue was normal and pancreatic lobule was intact. There was no inflammatory cell infiltration, hyperemia and necrotic tissue in the interstitium. After $5 \%$ sodium taurocholate was retrograde injected into pancreatic duct of rats to establish AP rat model, many pancreatic acinar cells showed necrosis with fuzzy structure and fused into one piece in AP group. The structure of pancreatic lobule was blurred, along with inflammatory cells infiltration. After modafinil treatment, histologic assessment of pancreatic damage showed that cell necrosis, inflammatory cell infiltration and interstitial edema were significantly ameliorated in rats with acute pancreatitis comparing to AP group (Fig. 1A), along with significantly decreased ascites $(p<0.01$, Fig. 1B). Schmidt pathology

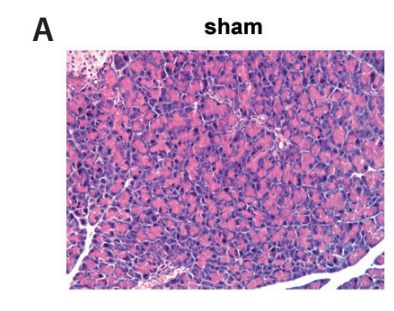

B

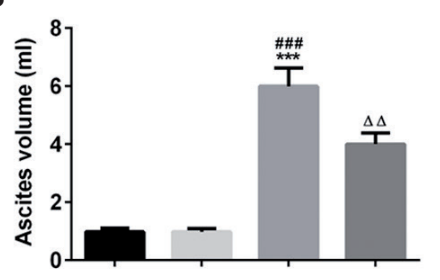

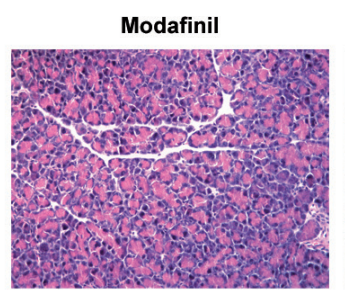

C
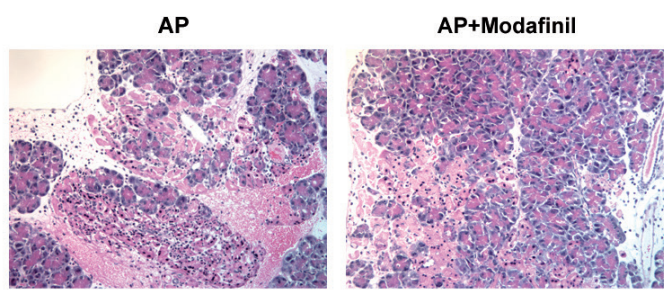

D
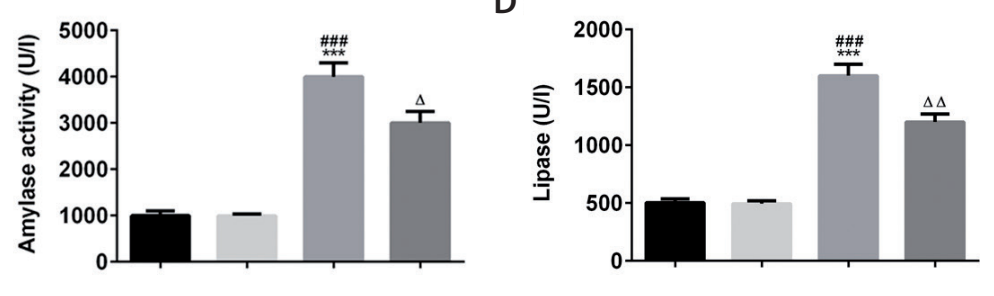

sham

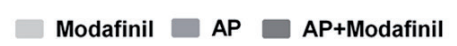

Figure 1. A. Pancreatic damage was detected by H\&E stainning. B. Modafinil significantly reduced ascites extracted with a $5 \mathrm{ml}$ syringe in acute pancreatitis rats. C, D. Amylase and lipase levels in serum were measured through amylase and lipase assay kit in acute pancreatitis rats, respectively. All data are shown as mean $\pm \mathrm{SD}, n=10 .{ }^{* * *} p<0.001$ vs. Modafinil group; ${ }^{\# \#} p<0.001$ vs. Sham group; ${ }^{\Delta} p<0.05$, ${ }^{\Delta \Delta} p<0.01$ vs. AP group. AP, acute pancreatitis. 

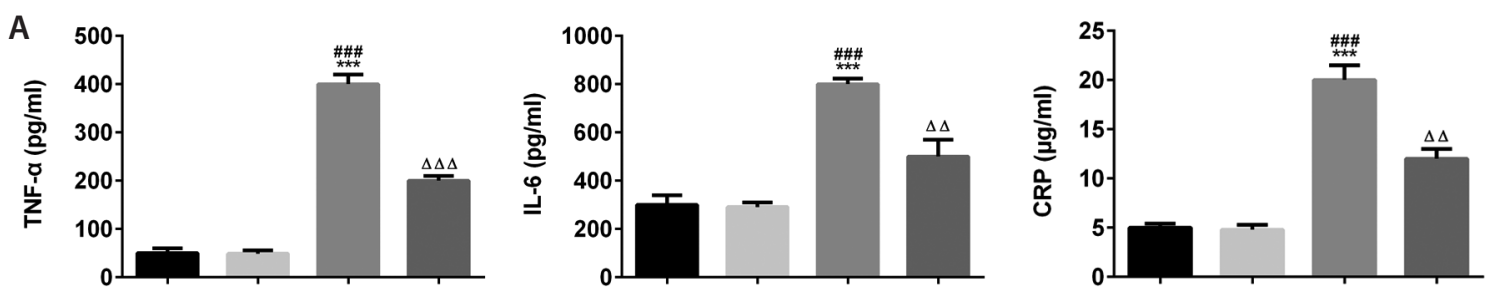

B

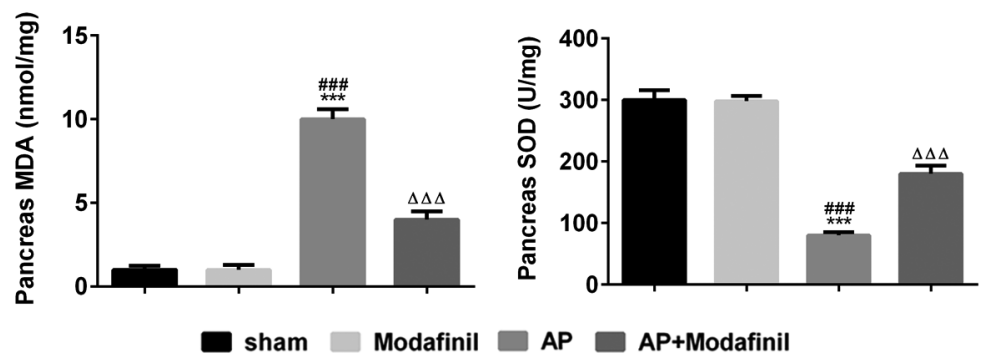

Figure 2. A. Inflammatory markers TNF- $\alpha$, IL- 6 and CRP were detected in serum by ELISA. B. Oxidative stress markers MDA and SOD were detected in pancreatic tissue. All data are shown as mean $\pm \mathrm{SD}, n=$ $10 .{ }^{* * *} p<0.001 v s$. Modafinil group; $\# \#$ \# $<0.001 v s$. Sham group; ${ }^{\Delta \Delta} p<$ $0.01,{ }^{\Delta \Delta \Delta} p<0.001 v s$. AP group.

score in AP group was markedly increased comparing to sham group. Besides, modafinil administration significantly reduced Schmidt pathology score in rats of $\mathrm{AP}+$ modafinil group comparing to AP group ( $p<0.01$, Table 2$)$. Amylase and lipase levels in serum also markedly were decreased by modafinil administration $(p<0.05$, Fig. $1 C, D)$.
A

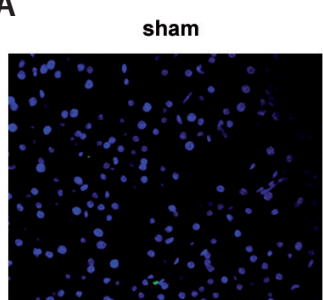

AP

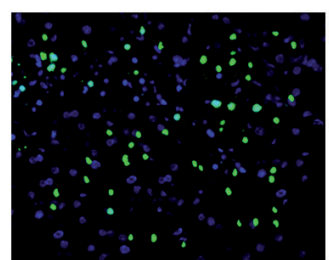

B

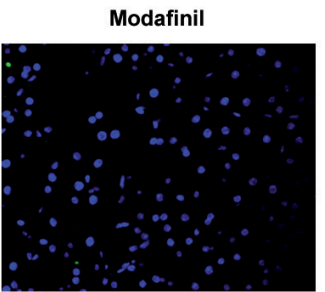

AP+Modafinil

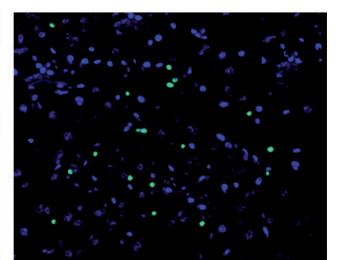

Bcl-2

Cleaved

caspase-3

Pro-caspase-3

Bax

GAPDH
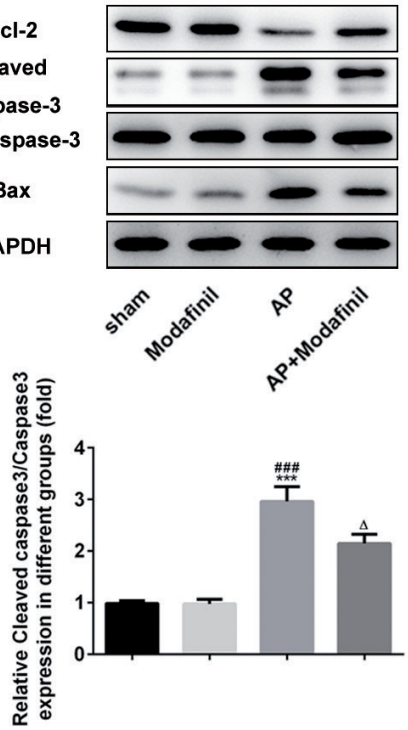
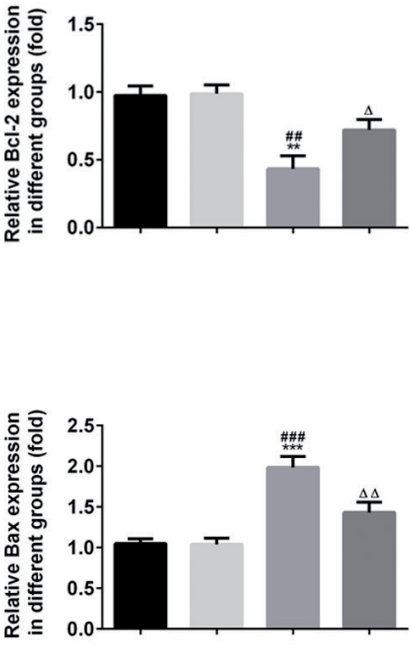

C

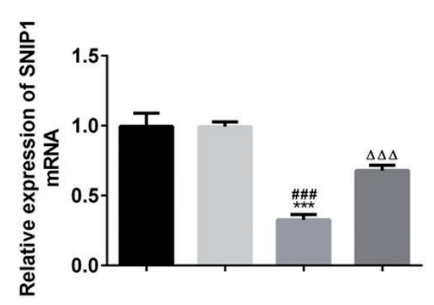

SNIP1

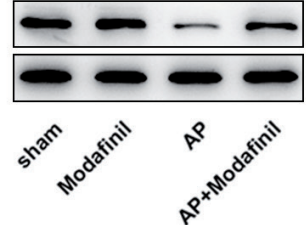

D

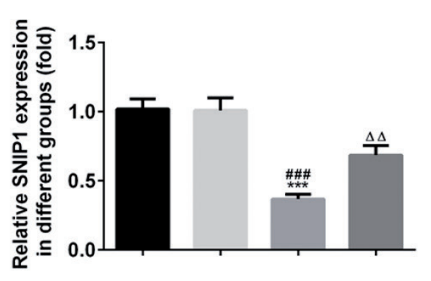

sham Modafinil $\square$ AP

AP+Modafinil

Figure 3. A. Apoptotic cells were detected in pancreatic tissue by tunnel staining. B. Apoptosis-related proteins were detected by Western blotting. SNIP1 expression was analyzed by qPCR $(\mathbf{C})$ and Western blotting (D). All data are shown as mean \pm SD, $n=10 .{ }^{* *} p<$ $0.01,{ }^{* * *} p<0.001$ vs. Modafinil group; ${ }^{\# \#} p<0.01,{ }^{\# \#} p<0.001$ vs. Sham group; ${ }^{\Delta} p<0.05,{ }^{\Delta \Delta} p<0.01,{ }^{\Delta \Delta \Delta} p<0.001$ vs. AP group. 
Modafinil significantly reduced inflammation and oxidative stress in AP rats

To assess the inflammatory levels and oxidative stress in AP rats, inflammatory markers (TNF- $\alpha$, IL-6, CRP) in serum and oxidative stress markers (MDA, SOD) were detected via specific kits in pancreatic tissue. The results revealed that AP-increased levels of TNF- $\alpha$, IL- 6 and CRP were markedly reduced when modafinil was administered; MDA was decreased and SOD was increased after administration of modafinil to AP rats $(p<0.01$, Fig. $2 \mathrm{~A}, \mathrm{~B})$.

\section{Modafinil significantly decreased apoptosis and increased SNIP1 levels}

The cell apoptosis levels were evaluated by TUNNEL staining and apoptosis-related proteins levels in pancreatic tissue. Modafinil significantly reduced the number of apoptotic cells (showed green fluorescence) in acute pancreatitis rats (Fig. 3A). Simultaneously, anti-apoptosis protein (Bcl-2) levels were significantly increased, and pro-apoptosis proteins (Bax and cleaved caspase-3) levels were markedly decreased under modafinil treatment of AP rats $(p<0.05$, Fig. $3 \mathrm{~B})$. The SNIP1 levels were also measured through qPCR and Western blotting. The results illustrated that SNIP1 levels were upregulated in rats of AP group. However, modafinil could distinctly downregulated SNIP1 expression in AP rats $(p<0.001$, Fig. 3 C).
Modafinil dramatically increased cell viability and SNIP1 levels in CR and LPS-induced AR42J cells

Next step, whether modafinil had direct effects on AR42J cells in vitro were investigated. Modafinil treatment didn't affect the cell vitality of normal AR42J cells (Fig. 4A). Differently, modafinil obviously increased cell viability of AP cells in a dose-dependent manner ( $p<0.01$, Fig. $4 B)$. Here, $10 \mathrm{nM}$ of modafinil was used to perform further experiments. We found that SNIP1 expression was significantly decreased in AP cells, which could be significantly increased upon modafinil treatment $(p<0.05$, Fig. 4 C, D).

\section{Modafinil lessened inflammation and oxidative stress through SNIP1 in CR and LPS-induced AR42J cells}

SNIP1 knockdown plasmids (shRNA-SNIP1-1, shRNASNIP1-2) were separately transfected into different groups of cells. The results exhibited that the suppressive effect of shRNA-SNIP1-1 on SNIP1 expression was better than that of shRNA-SNIP1-2 ( $p<0.01$, Fig. 5A). Thus, shRNA-SNIP1-1 was selected for later experiments. Then, we analyzed the effects of modafinil on amylase, lipase, inflammation and oxidative stress in AP cells and explored its mechanism. SNIP1 knockdown significantly reversed the inhibitory effects of modafinil on amylase, lipase, inflammation response and oxidative stress in AP cells $(p<0.05$, Fig. 5B, D).
A

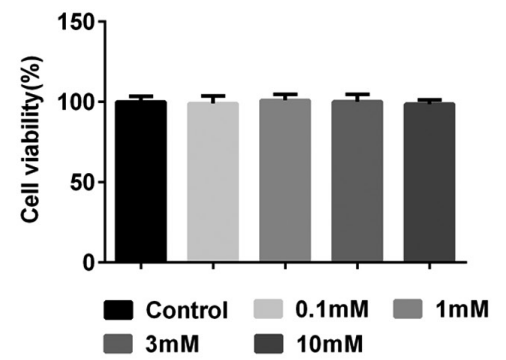

B

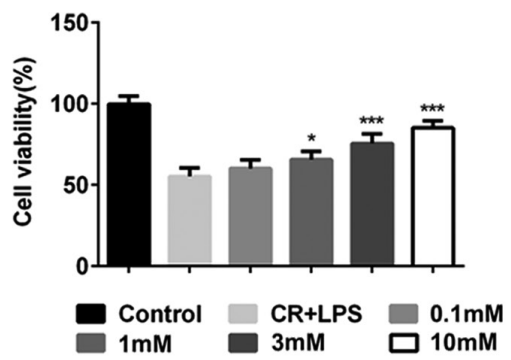

\section{$\mathrm{C}$}

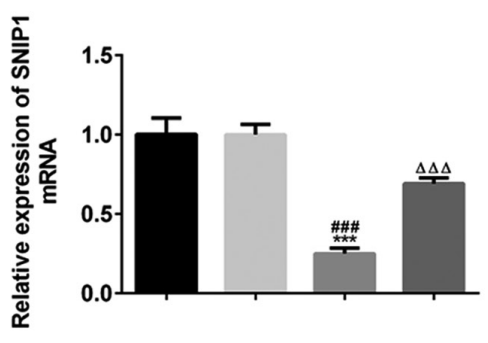

D
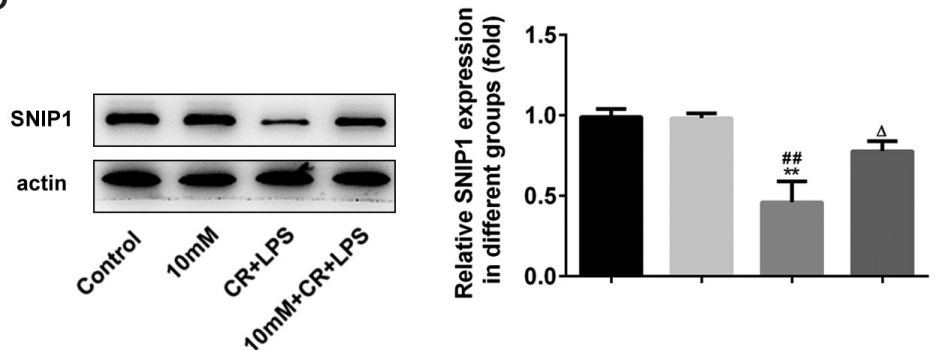

Control $\square 10 \mathrm{mM} \square$ CR+LPS $\square 10 \mathrm{mM}+\mathrm{CR}+\mathrm{LPS}$

Figure 4. A. AR42J cells vitality was detected by CCK8 assay after modafinil (0.1, 1, 3 and $10 \mathrm{mM})$ treatment. B. Modafinil pretreatment $(0.1,1,3,10 \mathrm{mM})$ markedly increased cells vitality induced by cerulein $(0.5 \mathrm{nM})$ and lipopolysaccharide $(1.0 \mu \mathrm{g} / \mathrm{ml})(\mathrm{CR}+\mathrm{LPS}) .{ }^{\star} p<$ $0.05,{ }^{* * *} p<0.001 v s$.CR+LPS group. C, D. Modafinil significantly recovered SNIP1 levels that were decreased by CR+LPS treatment. $10 \mathrm{mM}$, Control group treated using $10 \mathrm{mM}$ modafinil. All data are shown as mean $\pm \mathrm{SD}, n=10 .{ }^{* *} p<0.01,{ }^{* *} p<0.001 v s$. Control group; ${ }^{\# \#} p<0.01,{ }^{\# \# \#} p<0.001$ vs. $10 \mathrm{mM}$ group; ${ }^{\Delta} p<0.5,{ }^{\Delta \Delta \Delta} p<0.001$ vs. CR+LPS group. 
A

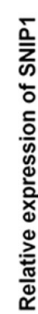

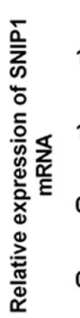

C

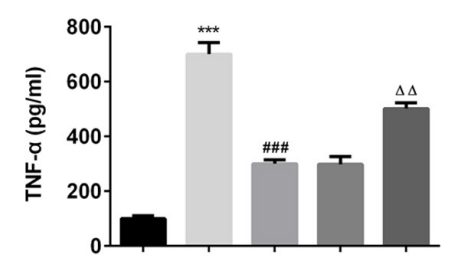

D

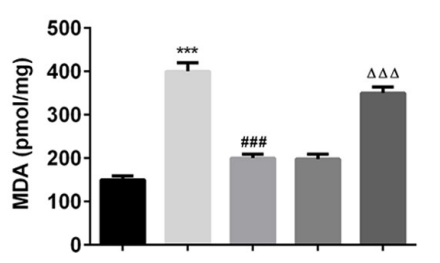

B
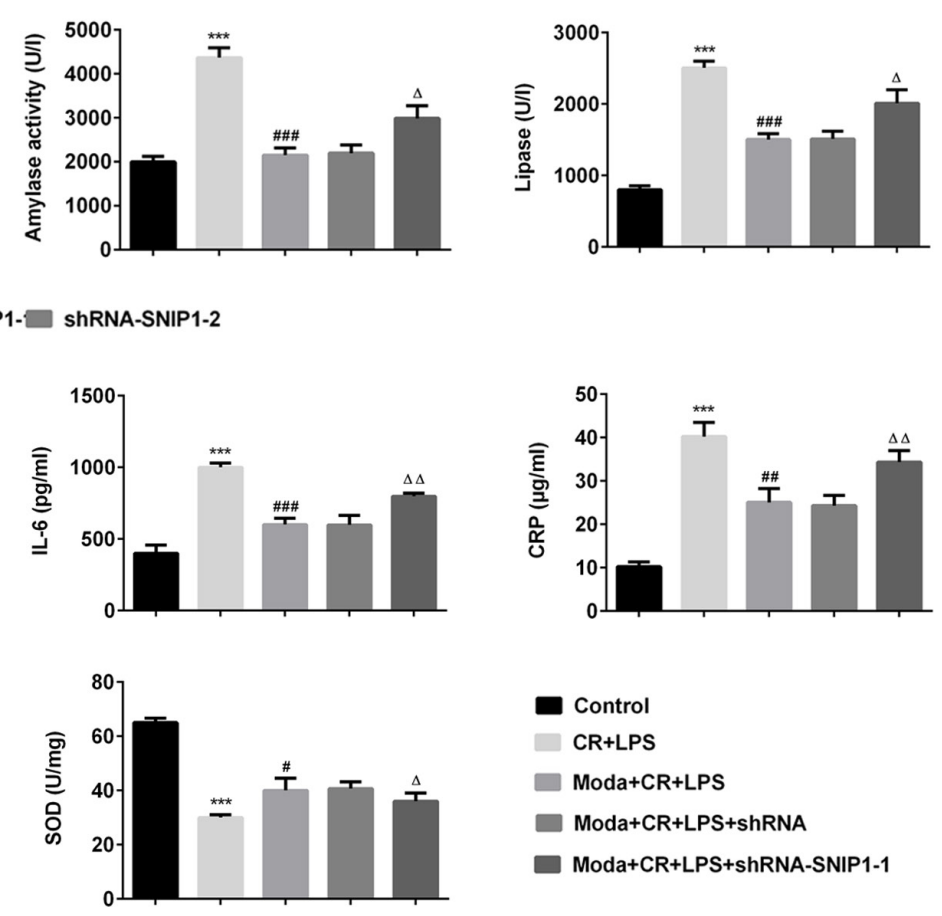

Control

CR+LPS

Moda+CR+LPS

Moda+CR+LPS+shRNA

Moda+CR+LPS+shRNA-SNIP1-1

Figure 5. A. SNIP1 mRNA levels were detected by qPCR. ${ }^{* *} p<0.01$ compared with shRNA-SNIP1-1, ${ }^{* * *} p<0.001 v s$. shRNA (expressing scrambled SNIP1). B. SNIP1 significantly affected the effects of modafinil on amylase and lipase. C, D. SNIP1 significantly affected the effects of modafinil on inflammation and oxidative stress. All data shown as mean $\pm \mathrm{SD}, n=10{ }^{* * *} p<0.001$ vs. Control group; ${ }^{\#} p<0.05,{ }^{\# \#} p<0.01,{ }^{\# \# \#} p<0.001$ vs. CR+LPS group; ${ }^{\Delta} p<0.5,{ }^{\Delta \Delta} p<0.01,{ }^{\Delta \Delta \Delta} p<0.001 v s$. Moda+CR+LPS+shRNA group. CR+LPS, cerulein $(0.5 \mathrm{nM})$ and lipopolysaccharide $(1.0 \mu \mathrm{g} / \mathrm{ml})$; Moda, modafinil. (For more details see Methods).

\section{Modafinil mitigated apoptosis through SNIP1 in CR and LPS-induced AR42J cells}

The AP-induced apoptotic levels were significantly decreased by modafinil treatment and these phenomena were significantly reversed after SNIP1 was silenced $(p<0.01$, Fig. $6 \mathrm{~A})$. Besides, modafinil decreased pro-apoptosis proteins, cleaved caspased-3 and Bax levels in AP cells, accompanied by increased anti-apoptosis protein $\mathrm{Bcl}-2$. Simultaneously, the effects of modafinil in AP cells could be reversed by decreasing endogenous expression of SNIP1 $(p<0.05$, Fig. $6 \mathrm{~B}, \mathrm{C})$. The result indicated that modafinil might regulate mitochondrial-mediated apoptosis pathway through SNIP1.

\section{Discussion}

AP has been widely regarded as inflammation disorder and presents excess release of pro-inflammatory factors including IL-6, IL-8 and TNF- $\alpha$ (Pooran et al. 2003). In this study, modafinil treatment significantly reduces IL-6, TNF- $\alpha$ and CRP levels in the serum of AP rats, replying that modafinil might repress pro-inflammatory process to some extent. The studies have demonstrated that inflammation response in AP could be regulated by $\mathrm{p} 38$ MAPK pathway or microRNA, which implied that modafinil might also reduce inflammation through affecting aforementioned substance ( $\mathrm{Gu}$ et al. 2019; Wan et al. 2019).

A recent study has shown that modafinil can inhibit $\mathrm{T}$ helper 1 cells to mediate anti-inflammatory response in experimental autoimmune encephalomyelitis (Brandao et al. 2019). We discovered that the pathological damage was significantly improved by modafinil in the present study. SNIP1 is demonstrated to mediate the inhibition of TGF- $\beta$ downstream target genes, which can further ameliorate the pathological injury of pancreas and decrease amylase levels in AP (Tasci et al. 2019).

The primary substrate of caspase- 3 is the poly (ADPribose) polymerase (PARP), which participates in DNA repair and gene integrity monitoring. The cell apoptosis induced by caspase- 3 can be blocked by Bcl-2. Our study uncovered that modafinil significantly inhibited pro-apoptotic proteins containing Bax and cleaved caspase- 3 and enhanced anti-apoptotic protein Bcl-2. Furthermore, results of TUNNEL staining showed reduced apoptotic cells after modafinil treatment. These data replied that apoptosis was 


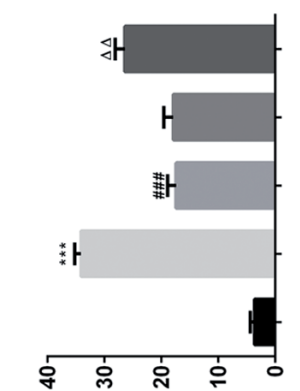

(\%) s!̣soldode ॥əכ

$\infty$
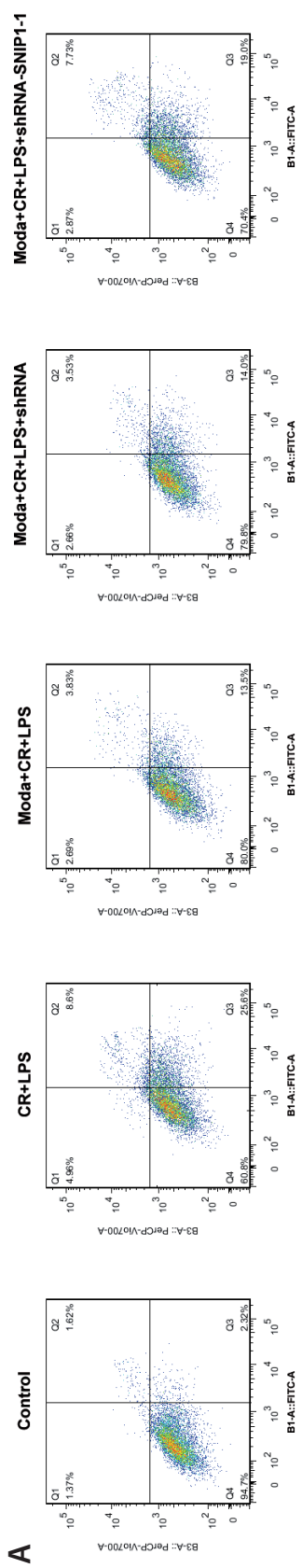

.

응

인

कृ

荧 $\triangleleft$

के

可证

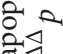

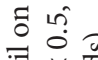

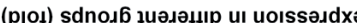

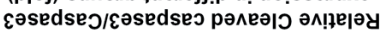

$\bar{\exists} \vee$

可 4 政

:

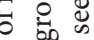

足 $\infty$

要要

幽。

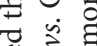

究 $\overrightarrow{8}$

o.

$\checkmark v$

岛萎

艺

है

范

훌

बㄷํㅇ है

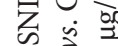

نे

安

$\circ \vee$

응 즌

这

च

ธ능

릉

c)

घ

放

这

的

苞

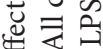

舟

려웡

苞 宇豈

表

क

音

云寻

क

号

< :

빈

言 
significantly hampered by administration of modafinil. In AP cell model, modafinil markedly reduced cell impairment, apoptosis, inflammation and oxidative stress via regulating SNIP1 levels. These findings replied that modafinil might inhibit TGF- $\beta$ pathway, therefore regulating the pathway affecting cellular activities via SNIP1. However, this hypothesis needs further study. Although there is a controversy about the functions of TGF- $\beta$ in apoptosis and inflammation in pancreas disease, more and more studies have indicated that the inhibition of TGF- $\beta$ pathway reduces pancreas damage in AP (Zhou et al. 2019). Moreover, TGF- $\beta$, TNF- $\alpha$ and ROS levels mediate the progression of apoptosis. Finally, $\mathrm{Bcl}-2$ was increased, along with decreased caspase-3 levels (Schuster and Krieglstein 2002).

A study has suggesting that modafinil significantly reduces MDA and NF- $\kappa B$ levels in animal models and exerts protective effects (Yousefi-Manesh et al. 2019a, 2019b). The result was similar to the finding in our study. MDA and SOD levels are frequently used to evaluate the oxidative stress levels in AP (Tasci et al. 2019). The increased ROS production beyond anti-oxidative abilities mostly appears in activated neutrophils, which infiltrates pancreas, activates digestive enzymes in acinar cells and results in the self-digestion of pancreas (Tsai et al. 1998; Andican et al. 2005). In our study, MDA levels were decreased but SOD levels were increased, indicating that oxidative stress was decreased by modafinil treatment to some degree. In AP rat model, SNIP1 levels in pancreatic tissue were significantly down-regulated, as the GEO database showed. After modafinil treatment, the expression of SNIP1 was significantly recovered, along with decreased inflammation, oxidative stress and cell apoptosis. In AP cell model, the SNIP1 knockdown inhibited the protective effects of modafinil via repressing inflammation, oxidative stress and apoptosis. The results indicated that modafinil might develop significantly therapeutic effects by regulating SNIP1 levels. The study showed that modafinil ameliorated pancreatic injury and inflammation through upregulating SNIP1 through an in vivo and vitro study. Modafinil could be a potential therapeutic drug in decreasing pancreatic injury in AP.

Conflict of interest. The authors declared no conflict of interest.

Acknowledgements. The study was support by Suzhou key medical discipline (SZXK201808), People's Livelihood Science and Technology Project of Suzhou Science and Technology Bureau (SYS201769) and Suzhou Health and Family Planning Commission Project (LCZX201711).

\section{Reference}

Andican G, Gelisgen R, Unal E, Tortum OB, Dervisoglu S, Karahasanoglu T, Burcak G (2005): Oxidative stress and nitric oxide in rats with alcohol-induced acute pancreatitis. World J. Gastroenterol. 11, 2340-2345

https://doi.org/10.3748/wjg.v11.i15.2340

Brandao WN, Andersen ML, Palermo-Neto J, Peron JP, Zager A (2019): Therapeutic treatment with Modafinil decreases the severity of experimental autoimmune encephalomyelitis in mice. Int. Immunopharmacol. 75, 105809 https://doi.org/10.1016/j.intimp.2019.105809

Cao Y, Li Q, Liu L, Wu H, Huang F, Wang C, Lan Y, Zheng F, Xing F, Zhou Q, et al. (2019): Modafinil protects hippocampal neurons by suppressing excessive autophagy and apoptosis in mice with sleep deprivation. Br. J. Pharmacol. 176, 1282-1297 https://doi.org/10.1111/bph.14626

Chen B, Huang S, Su Y, Wu YJ, Hanna A, Brickshawana A, Graff J, Frangogiannis NG (2019): Macrophage Smad3 protects the infarcted heart, stimulating phagocytosis and regulating inflammation. Circ. Res. 125, 55-70 https://doi.org/10.1161/CIRCRESAHA.119.315069

Chen LL, Lin HP, Zhou WJ, He CX, Zhang ZY, Cheng ZL, Song JB, Liu P, Chen XY, Xia YK, et al. (2018): SNIP1 recruits TET2 to regulate c-MYC target genes and cellular DNA damage response. Cell. Rep. 25, 1485-1500.e4

https://doi.org/10.1016/j.celrep.2018.10.028

Chen X, Xue F, Xie T, Luo C (2013): Silencing of the Smad nuclear interacting protein 1 (SNIP1) by siRNA inhibits proliferation and induces apoptosis in pituitary adenoma cells. Tumour Biol. 34, 3071-3076

https://doi.org/10.1007/s13277-013-0873-1

Chu X, Wu S, Raju R (2019): NLRX1 regulation following acute mitochondrial injury. Front. Immunol. 10, 2431 https://doi.org/10.3389/fimmu.2019.02431

Gu L, Liu J, Xu D, Lu Y (2019): Reciprocal feedback loop of the MALAT1-microRNA-194-YAP1 pathway regulates progression of acute pancreatitis. Med. Sci. Monit. 25, 6894-6904 https://doi.org/10.12659/MSM.915598

Han J, Chen D, Liu D, Zhu Y (2018): Modafinil attenuates inflammation via inhibiting Akt/NF-kappaB pathway in apoE-deficient mouse model of atherosclerosis. Inflammopharmacology 26, 385-393 https://doi.org/10.1007/s10787-017-0387-3

Jung JC, Lee Y, Son JY, Lim E, Jung M, Oh S (2012): Simple synthesis of modafinil derivatives and their anti-inflammatory activity. Molecules 17, 10446-10458 https://doi.org/10.3390/molecules 170910446

Komolafe O, Pereira SP, Davidson BR, Gurusamy KS (2017): Serum $\mathrm{C}$-reactive protein, procalcitonin, and lactate dehydrogenase for the diagnosis of pancreatic necrosis. Cochrane Database Syst. Rev. 4, Cd012645 https://doi.org/10.1002/14651858.CD012645

Liao NC, Shih YL, Chou JS, Chen KW, Chen YL, Lee MH, Peng SF, Leu SJ, Chung JG (2019): Cardamonin induces cell cycle arrest, apoptosis and alters apoptosis associated gene expression in WEHI-3 mouse leukemia cells. Am. J. Chin. Med. 47, 635-656 https://doi.org/10.1142/S0192415X19500332

Lillicrap T, Krishnamurthy V, Attia J, Nilsson M, Levi CR, Parsons MW, Bivard A (2016): Modafinil in debilitating fatigue after stroke (MIDAS): study protocol for a randomised, doubleblinded, placebo-controlled, crossover trial. Trials 17, 410 
https://doi.org/10.1186/s13063-016-1537-4

Liu S, Long J, Yuan B, Zheng M, Xiao M, Xu J, Lin X, Feng XH (2016): SUMO modification reverses inhibitory effects of Smad nuclear interacting protein-1 in TGF-beta responses. J. Biol. Chem. 291, 24418-27430 https://doi.org/10.1074/jbc.M116.755850

Liu Y, Chen XD, Yu J, Chi JL, Long FW, Yang HW, Chen KL, Lv ZY, Zhou B, Peng ZH, et al. (2017): Deletion Of XIAP reduces the severity of acute pancreatitis via regulation of cell death and nuclear factor-kappaB activity. Cell Death Dis. 8, e2685 https://doi.org/10.1038/cddis.2017.70

Liu Z, Lai K, Ying X, He X, Zhou X (2018): Gli2 mediated activation of hedgehog signaling attenuates acute pancreatitis via balancing inflammatory cytokines in mice. Cell. Physiol. Biochem. 48, $120-130$ https://doi.org/10.1159/000491668

Lu YY, Xu DC, Zhao YF, Zhu GF, Zhu MY, Liu WJ, Yu XJ, Chen W, Liu Z, Xu YW (2016): Smad nuclear interacting protein 1 acts as a protective regulator of pressure overload-induced pathological cardiac hypertrophy. J. Am. Heart Assoc. 5, e003943 https://doi.org/10.1161/JAHA.116.003943

Pooran N, Indaram A, Singh P, Bank S (2003): Cytokines (IL-6, IL-8, TNF): early and reliable predictors of severe acute pancreatitis. J. Clin. Gastroenterol. 37, 263-266 https://doi.org/10.1097/00004836-200309000-00013

Schlegel M, Korner A, Kaussen T, Knausberg U, Gerber C, Hansmann G, Jonasdottir HS, Giera M, Mirakaj V (2019): Inhibition of neogenin fosters resolution of inflammation and tissue regeneration. J. Clin. Invest. 129, 2165 https://doi.org/10.1172/JCI128681

Schmitz-Winnenthal H, Pietsch DH, Schimmack S, Bonertz A, Udonta F, Ge Y, Galindo L, Specht S, Volk C, Zgraggen K, et al. (2010): Chronic pancreatitis is associated with diseasespecific regulatory T-cell responses. Gastroenterology 138, 1178-1188 https://doi.org/10.1053/j.gastro.2009.11.011

Schuster N, Krieglstein K (2002): Mechanisms of TGF-betamediated apoptosis. Cell. Tissue Res. 307, 1-14 https://doi.org/10.1007/s00441-001-0479-6

Shi Y, He C, Ma C, Yu T, Cong Y, Cai W, Liu Z (2018): Smad nuclear interacting protein 1 (SNIP1) inhibits intestinal inflammation through regulation of epithelial barrier function. Mucosal. Immunol. 11, 835-845 https://doi.org/10.1038/mi.2017.95

Steinberg WM, Buse JB, Ghorbani MLM, Orsted DD, Nauck MA (2017): Amylase, lipase, and acute pancreatitis in people with type 2 diabetes treated with liraglutide: results from the LEADER randomized trial. Diabetes Care 40, 966-972 https://doi.org/10.2337/dc16-2747

Tasci S, Senocak R, Lapsekili E, Kaymak S, Yigit T (2019): The effects of a TNF-alpha inhibitor and $\mathrm{HBO}$ combination on the severity of pancreatitis and oxidative response in an experimental model of acute pancreatitis. Bratisl. Lek. Listy 120, 417-422 https://doi.org/10.4149/BLL_2019_067

Tsai K, Wang SS, Chen TS, Kong CW, Chang FY, Lee SD, Lu FJ (1998): Oxidative stress: an important phenomenon with pathogenetic significance in the progression of acute pancreatitis. Gut 42, 850-855 https://doi.org/10.1136/gut.42.6.850

Vaccarino SR, McInerney SJ, Kennedy SH, Bhat V (2019): The potential procognitive effects of modafinil in major depressive disorder: a systematic review. J. Clin. Psychiatry 80,19r12767 https://doi.org/10.4088/JCP.19r12767

Wan YD, Zhu RX, Bian ZZ, Pan XT (2019): Improvement of Gut Microbiota by inhibition of P38 mitogen-activated protein kinase (MAPK) signaling pathway in rats with severe acute pancreatitis. Med. Sci. Monit. 25, 4609-4616 https://doi.org/10.12659/MSM.914538

Yang Q, Ren GL, Wei B, Jin J, Huang XR, Shao W, Li J, Meng XM, Lan HY (2019): Conditional knockout of TGF-betaRII /Smad2 signals protects against acute renal injury by alleviating cell necroptosis, apoptosis and inflammation. Theranostics $\mathbf{9}$, 8277-8293 https://doi.org/10.7150/thno.35686

Yousefi-Manesh H, Rashidian A, Hemmati S, Shirooie S, Sadeghi MA, Zarei N, Dehpour AR (2019a): Therapeutic effects of modafinil in ischemic stroke; possible role of NF-kappaB downregulation. Immunopharmacol. Immunotoxicol. 41, 558-564 https://doi.org/10.1080/08923973.2019.1669045

Yousefi-Manesh H, Shirooie S, Hemati S, Shokrian-Zeini M, Zarei N, Raoufi M, Farrokhi V, Dehpour AR (2019b): Protective effects of modafinil administration on testicular torsion/detorsion damage in rats. Exp. Mol. Pathol. 111, 104305 https://doi.org/10.1016/j.yexmp.2019.104305

Zhou Q, Xia S, Guo F, Hu F, Wang Z, Ni Y, Wei T, Xiang H, Shang D (2019): Transforming growth factor-beta in pancreatic diseases: Mechanisms and therapeutic potential. Pharmacol. Res. 142, 58-69 https://doi.org/10.1016/j.phrs.2019.01.038

Received: December 23, 2019

Final version accepted: April 30, 2020 